\section{(1)}

CrossMark

\title{
Effects of exercise and airway clearance (positive expiratory pressure) on mucus clearance in cystic fibrosis: a randomised crossover trial
}

\author{
Tiffany J. Dwyer ${ }^{1,2}$, Evangelia Daviskas², Rahizan Zainuldin ${ }^{1,3,4}$, \\ Jordan Verschuer ${ }^{5}$, Stefan Eberl ${ }^{5}$, Peter T.P. Bye ${ }^{2,6}$ and Jennifer A. Alison ${ }^{1,7}$
}

Affiliations: ${ }^{1}$ Discipline of Physiotherapy, Faculty of Health Sciences, University of Sydney, Sydney, Australia. ${ }^{2}$ Dept of Respiratory and Sleep Medicine, Royal Prince Alfred Hospital, Sydney, Australia. ${ }^{3}$ Rehabilitation Dept, $\mathrm{Ng}$ Teng Fong General Hospital, Jurong Campus, NUHS Group, Singapore. ${ }^{2}$ Physiotherapy, Health and Social Sciences Cluster, Singapore Institute of Technology, Singapore. ${ }^{5}$ Dept of PET and Nuclear Medicine, Royal Prince Alfred Hospital, Sydney, Australia. ${ }^{6}$ Central Clinical School, Sydney Medical School, University of Sydney, Sydney, Australia. ${ }^{7}$ Sydney Local Health District, Sydney, Australia.

Correspondence: Tiffany J. Dwyer, Discipline of Physiotherapy, University of Sydney, PO Box 170, Lidcombe NSW 1825, Australia. E-mail: tiffany.dwyerdsydney.edu.au

@ERSpublications

Exercise and PEP therapy significantly improve mucus clearance in CF, but PEP therapy clears more mucus than exercise alone http://ow.ly/d7j530nvUOM

Cite this article as: Dwyer TJ, Daviskas E, Zainuldin R, et al. Effects of exercise and airway clearance (positive expiratory pressure) on mucus clearance in cystic fibrosis: a randomised crossover trial. Eur Respir J 2019; 53: 1801793 [https://doi.org/10.1183/13993003.01793-2018].

ABSTRACT Exercise improves mucus clearance in people without lung disease and those with chronic bronchitis. No study has investigated exercise alone for mucus clearance in cystic fibrosis (CF). The aim of this study was to compare the effects of treadmill exercise to resting breathing and airway clearance with positive expiratory pressure (PEP) therapy on mucus clearance in adults with CF.

This 3-day randomised, controlled, crossover trial included 14 adults with mild to severe CF lung disease (forced expiratory volume in $1 \mathrm{~s} \%$ predicted 31-113\%). Interventions were $20 \mathrm{~min}$ of resting breathing (control), treadmill exercise at $60 \%$ of the participant's peak oxygen consumption or PEP therapy (including huffing and coughing). Mucus clearance was measured using the radioaerosol technique and gamma camera imaging.

Treadmill exercise improved whole lung mucus clearance compared to resting breathing (mean difference $3 \%$, 95\% CI 2-4); however, exercise alone was less effective than PEP therapy (mean difference $-7 \%, 95 \%$ CI -6- -8). When comparing treadmill exercise to PEP therapy, there were no significant differences in mucus clearance from the intermediate and peripheral lung regions, but significantly less clearance from the central lung region (likely reflecting the huffing and coughing that was only in PEP therapy).

It is recommended that huffing and coughing are included to maximise mucus clearance with exercise.

This article has supplementary material available from erj.ersjournals.com

Received: Sept 212018 | Accepted after revision: Jan 232019

This study is registered with the Australian and New Zealand Clinical Trials Registry (www.anzctr.org.au) with registration number ACTRN12608000287336. Individual participant data are available as a supplementary file. The study protocol will be made available on request to the corresponding author.

Copyright OERS 2019 


\section{Introduction}

People with cystic fibrosis (CF) produce large amounts of thick mucus that is not cleared normally from the lungs, resulting in mucus retention and chronic lung damage [1]. Treatments to improve mucus clearance, including airway clearance therapies, remain a cornerstone of the standards of care and the respiratory management of CF lung disease [2-5]. These time-consuming therapies are required daily and adults with CF report performing an average of $108 \mathrm{~min}$ of treatment each day, with the majority of time taken up with airway clearance and exercise [6]. Exercise may aid secretion clearance in patients with CF [7-9]; however, there is no conclusive evidence to show if exercise can act as a substitute for established airway clearance treatments. Treatment time and burden for patients with CF would be reduced if exercise could replace airway clearance time whilst still reaping the known benefits of exercise training [10].

The most widely accepted technique to measure mucus clearance is to assess bronchial mucus transport, using a radioaerosol technique and imaging with a gamma camera $[11,12]$. Mucus clearance measured in this way is not confounded by sputum that is swallowed or saliva mixed with expectorated sputum. Individual physiological studies using this measurement procedure have investigated the effects of exercise and airway clearance techniques on mucus clearance compared to no intervention. Exercise has been shown to significantly increase mucus clearance in people without lung disease [13] and in adults with chronic bronchitis [14]. Several airway clearance techniques have been shown to significantly increase mucus clearance in adults with CF, including "conventional chest physiotherapy" (postural drainage combined with percussion and vibration) $[15,16]$; the forced expiratory technique (FET), which is relaxed breathing and huffing $[17,18]$; and positive expiratory pressure (PEP) therapy $[17,18]$. No specific airway clearance technique has been shown to be significantly more effective than other techniques [15-19]. Participants, however, report higher preference for techniques that can be done independently, e.g. with the use of PEP devices, compared to techniques performed on the patient by a healthcare professional or carer, e.g. percussion and vibration [20].

To date, no study has measured the effect of exercise alone on mucus clearance in adults with CF, nor compared exercise alone to an established airway clearance technique. For this study we have chosen to use PEP therapy as the airway clearance technique, because it has demonstrated both good efficacy and patient preference [20]. Therefore, the aim of this study was to determine the effect of treadmill exercise, compared to resting breathing (control) and PEP therapy, on mucus clearance and subjective responses in adults with CF. We hypothesised that treadmill exercise would be more effective than no intervention (control) and that treadmill exercise would be similarly effective to PEP therapy.

\section{Materials and methods}

Study design

A randomised, crossover trial was conducted, comprising four visits (figure 1). Participants were recruited from the Adult CF Clinic at Royal Prince Alfred Hospital, Sydney, Australia, and via an advertisement in the Cystic Fibrosis New South Wales newsletter. On visit 1, lung function and exercise capacity assessments were made prior to randomisation. Intervention order (one intervention per visit 2, 3 and 4) was determined by computer-generated randomisation, performed by a person not involved in the interventions and stored in sealed, sequentially numbered opaque envelopes. The three interventions were as follows: 1) constant-load treadmill exercise; 2) PEP plus FET (from now on referred to as PEP therapy); and 3) resting breathing (control). Each intervention was performed for $20 \mathrm{~min}$.

In order to standardise procedures, visits 2,3 and 4 were scheduled at the same time in the afternoon, separated by at least $48 \mathrm{~h}$ and within a 2 -week period (during which medication, airway clearance and exercise regimens were unchanged). Participants were asked to withhold routine mucolytic therapy and not to perform any airway clearance or exercise until after completing all procedures on a trial day. Participants withheld $\beta$-agonist medication for at least $8 \mathrm{~h}$ before any study visit, unless they had a history of exercise-induced bronchoconstriction. Those participants took $200 \mu \mathrm{g}$ of salbutamol via a metered dose inhaler and spacer $30 \mathrm{~min}$ before the peak treadmill test on visit 1 and the interventions on visits 2, 3 and 4. Outcomes were measured before the interventions, immediately after the interventions and during a 60-min period following the interventions. All outcome measures were later analysed by an assessor blinded to the intervention.

This trial was registered with the Australian and New Zealand Clinical Trials Registry (\#ACTRN12608000287336). Research procedures were approved by the Sydney South West Area Health Service Ethics Committee (RPAH Zone; protocol X08-0030) and participants provided written informed consent prior to data collection.

\section{Participants}

Patients were eligible for inclusion if they were $\geqslant 17$ years, had a confirmed diagnosis of CF (genetic testing and/or previous positive sweat test) and their treating physician deemed them to be clinically stable [21]. 


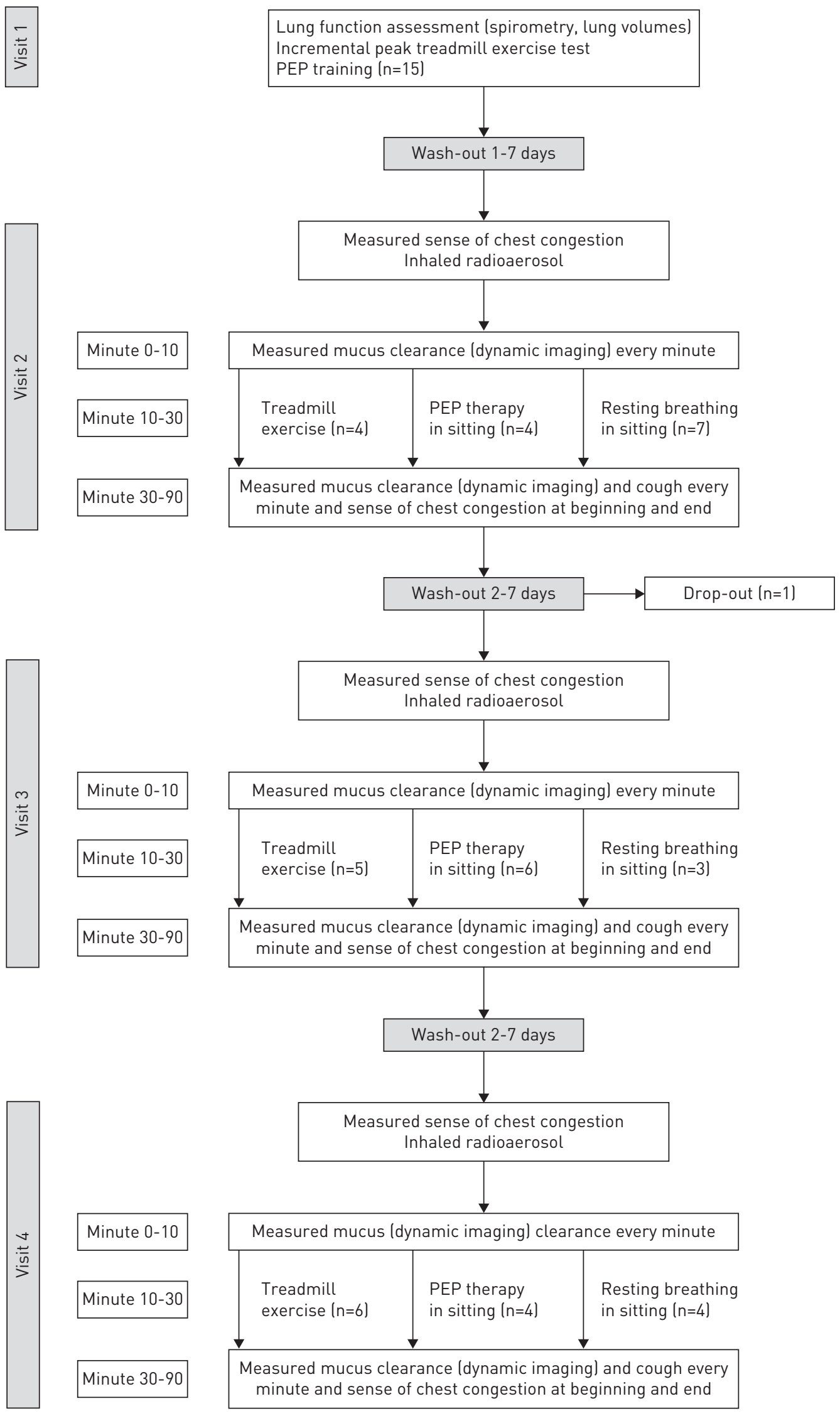

FIGURE 1 Design and flow of participants through the trial. PEP therapy: positive expiratory pressure therapy (including forced expiratory technique). 
Patients were excluded if they had received a lung transplant, were infected with Burkholderia cepacia complex, were pregnant or had exceeded the dose constraints from radiation exposure additional to normal clinical management, according to the Australian Radiation Protection and Nuclear Safety Agency code of practice for exposing humans to ionising radiation for research purposes [22]. Characteristics of participants (height, weight, spirometry, lung volumes and treadmill peak exercise capacity) were measured on visit 1 to describe the sample and individually prescribe the treadmill exercise intervention.

\section{Interventions}

For the exercise intervention, participants exercised on the treadmill for $20 \mathrm{~min}$ at a constant work rate equivalent to $60 \%$ of the peak oxygen consumption $\left(V^{\prime} \mathrm{O}_{2}\right.$ peak) achieved in the incremental peak treadmill test on visit 1 . This intensity and duration were chosen to replicate a typical prescription used for exercise training [23].

The PEP therapy intervention consisted of breathing through the PEP device for 15 breaths, followed by relaxed and deep breathing, huffing and coughing, according to the FET [24]. This cycle was repeated six times. The PEP hole diameter was chosen for each participant to achieve $10-20 \mathrm{cmH}_{2} \mathrm{O}$ in mid expiration [25]. Participants were taught to use the mouthpiece PEP device (PARI PEP System II; PARI, Starnberg, Germany) by a senior physiotherapist. If participants used PEP on a regular basis, corrections to their technique were made as necessary.

For the control intervention, participants received no intervention, i.e. they sat quietly for $20 \mathrm{~min}$.

\section{Outcome measures}

Mucus clearance

At each of visit 2, 3 and 4, subjects underwent a mucus clearance scan, which involved the inhalation of ${ }^{99} \mathrm{~m}$ Technecium (Tc)-labelled sulfur colloid. The procedure was as follows: 1) radioaerosol inhalation; 2) dynamic imaging over $10 \mathrm{~min}$ to assess initial deposition and baseline clearance of the radioaerosol; 3) 20-min intervention; 4) dynamic imaging over $60 \mathrm{~min}$ to assess post-intervention mucus clearance.

The primary outcome was mucus clearance, measured using the radioaerosol technique and dynamic imaging with a double-headed gamma camera (E.Cam; Siemens, Hoffman Estates, IL, USA) as reported previously by our group [26-34]. The radioaerosol, ${ }^{99 \mathrm{~m}}$ Tc-sulfur colloid (CIS-US Inc., Bedford, MA, USA) was generated by a jet nebuliser (mass median aerodynamic diameter of the particles of $5.5 \mu \mathrm{m}$, span 1.9; Medic-Aid, Peckham, UK) at $7 \mathrm{~L} \cdot \mathrm{min}^{-1}$. Subjects inhaled the radioaerosol whilst following a target on a computer screen to produce a controlled breathing pattern aimed at maximising deposition in the conducting airways: $450 \mathrm{~mL}$ tidal volume, short inspiratory time $(0.6-1.4 \mathrm{~s}$, individually set according to the participant's airway obstruction, with shorter time for those with less airway obstruction), $0.2 \mathrm{~s}$ inspiratory hold time and $2 \mathrm{~s}$ expiratory time. The breathing pattern aimed at a peak inspiratory flow of approximately $45 \mathrm{~L} \cdot \mathrm{min}^{-1}$. Approximately $5 \mathrm{~min}$ after radioaerosol inhalation, simultaneous anterior and posterior dynamic imaging commenced, with a 1-min frame rate and the patient in a supine position. In addition, on visit 2 only, the participant's lung fields were delineated from a transmission scan with a cobalt-57 sheet source before any other procedures were undertaken.

All images were decay-corrected to the imaging start time. The anterior and posterior emission images were combined into geometric mean images. The right lung was divided into central, intermediate and peripheral regions. The central region was a rectangle comprising the middle half of the vertical and horizontal dimensions of the right lung, and the intermediate and peripheral regions were concentric bands surrounding the central region [35]. The defined regions were stored as a template for use on each mucus clearance scan. The initial lung radioaerosol distribution was defined in terms of the penetration index, which is the ratio of mean counts per pixel in the peripheral region to mean counts per pixel in the central region, multiplied by 100 (with lower numbers representing more central deposition of the radioaerosol). The first image was obtained $5 \mathrm{~min}$ after radioaerosol inhalation. The total counts of the whole right lung and defined regions in the dynamic emission geometric mean images were expressed as a percentage of the counts at the end of the 10-min baseline scan (i.e. 100\% retained immediately before the intervention). Activity that had not been retained had been cleared. The mucus clearance scans were later analysed by an assessor blinded to the interventions.

Cough

All coughs (spontaneous and those directed according to the FET) were manually counted during each 20-min intervention and 60-min follow-up recovery period. 
Sense of chest congestion

Participants recorded their subjective sense of chest congestion on $10-\mathrm{cm}$ visual analogue scales $(0=$ very congested, 10=very clear) immediately before, during and at the end of $60 \mathrm{~min}$ following the intervention. The visual analogue scales were later measured by an assessor blinded to the interventions.

Data analysis

For the mucus clearance scans, a random coefficients model was fitted using general linear mixed models to model the relationship between the percentage of retention and time after the 20 -min intervention. The primary outcome was the mucus cleared immediately after finishing the 20-min intervention, measured by the intercept of the regression coefficient of retention. The secondary outcomes were the mean retention over the $60 \mathrm{~min}$ following the 20-min intervention, the subjective sense of chest congestion and the number of coughs. Repeated measures ANOVA were performed on the secondary outcome measures to compare differences between the interventions. Statistical significance was set at $\mathrm{p}<0.05$.

Data from a previous study involving eight subjects with chronic bronchitis resulted in a mean $\pm S D$ within-subject increase in mucus clearance with exercise of 7.5 \pm 5.8 [14]. Sample size calculations showed that 13 participants would be required to provide $90 \%$ power to detect the anticipated between-group differences in the primary outcome measure as significant $(\alpha=0.05)$. We sought to recruit 15 participants to allow for a $15 \%$ dropout and increase precision around our estimates.

\section{Results}

Flow of participants through the study

A total of 15 adults with mild to severe CF lung disease were recruited and 14 completed the study (one participant withdrew after visit 2 owing to an allergic reaction that may have been a delayed response to the inhaled radioaerosol). Participant baseline characteristics are presented in table 1 and the supplementary material [36-38]. Routine mucolytic therapy was hypertonic saline only for two participants; recombinant human deoxyribonuclease (rhDNase) only for three participants; both hypertonic saline and rhDNase for four participants; and both denufosol and rhDNase for one participant. No participant used mannitol and five participants did not use any mucolytic or osmotic medication. No participant was prescribed a cystic fibrosis transmembrane conductance regulator (CFTR) corrector or potentiator medication. All but one participant were prescribed bronchodilators and/or inhaled corticosteroids. Five participants with a history of exercise-induced bronchoconstriction took $200 \mu \mathrm{g}$ of salbutamol $30 \mathrm{~min}$ before the intervention on visits 2, 3 and 4 . All 15 participants performed exercise regularly when well and 14 performed some form of airway clearance routinely (four only exercised; five performed established airway clearance techniques only; five performed a combination of exercise and airway clearance techniques), including eight who performed PEP therapy on a regular basis.

There were no significant differences in the initial distribution of radioaerosol between the study days, with an mean \pm SD penetration index of $27.8 \pm 13.8$ for all scans, meaning that approximately 3.5 times the amount of radioaerosol was deposited in the central region compared to the peripheral region. There were no significant differences in pre-intervention mucus clearance during the 10-min baseline scan between any of the interventions (figure 2) and no carry-over or order effect between the interventions was detected.

\begin{tabular}{|c|c|c|}
\hline Characteristic ( $n=15)$ & Mean \pm sD & Range \\
\hline Age years & $27 \pm 9$ & $18-48$ \\
\hline Male sex $n$ \% & $10(67)$ & \\
\hline BMI $\mathrm{kg} \cdot \mathrm{m}^{-2}$ & $22.2 \pm 2.7$ & $18.1-27.4$ \\
\hline FEV 1 L & $2.45 \pm 0.94$ & $1.16-4.78$ \\
\hline FEV $1 \%$ pred & $65 \pm 23$ & $31-113$ \\
\hline FVC $\%$ pred & $88 \pm 18$ & $64-119$ \\
\hline FEV $1 / F V C$ & $0.61 \pm 0.16$ & $0.34-0.84$ \\
\hline $\mathrm{RV} / \mathrm{TLC} \%{ }^{\#}$ & $32 \pm 11$ & $10-50$ \\
\hline Treadmill V' $\mathrm{O}_{2 \text { peak }} \mathrm{mL} \cdot \mathrm{kg}^{-1} \cdot \mathrm{min}^{-1}$ & $36.1 \pm 10.4$ & $18.9-53.7$ \\
\hline Treadmill V' $0_{2 \text { peak }} \%$ pred & $94 \pm 25$ & 49-136 \\
\hline
\end{tabular}

BMI: body mass index; $F E V 1$ : forced expiratory volume in $1 \mathrm{~s}$; FVC: forced vital capacity; RV: residual volume; TLC: total lung capacity; $\mathrm{V}^{\prime} \mathrm{O}_{2}$ peak: peak oxygen uptake. ${ }^{\#}$ : RV/TLC reflects the degree of air trapping. 

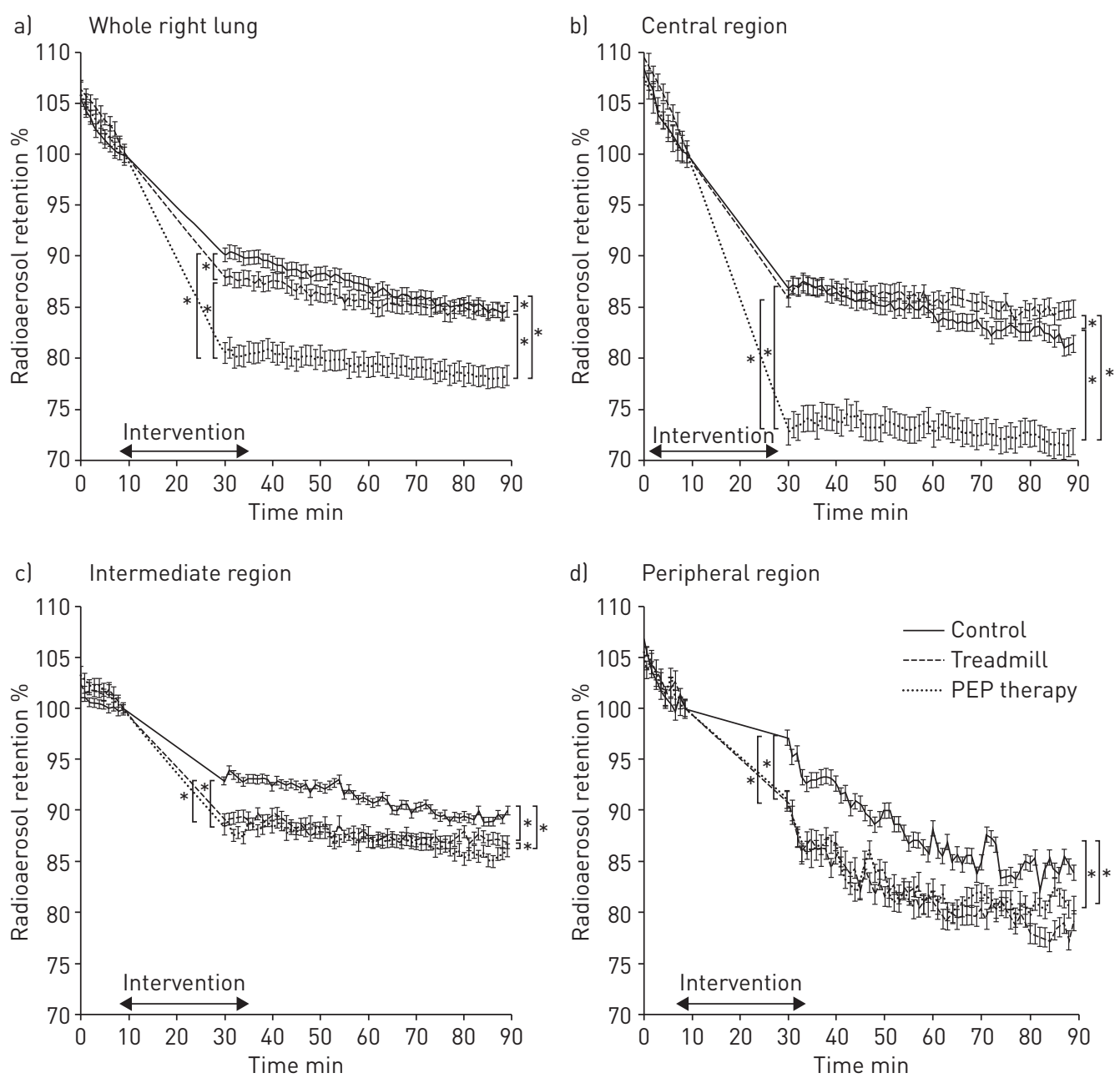

FIGURE 2 Mucus clearance scans for the control (solid line), treadmill exercise (dashed line) and positive expiratory pressure (PEP) therapy (dotted line) interventions (mean $\pm S E$ ), expressed as percentage of radioaerosol retention immediately before the intervention in a) whole right lung; b) central lung region; c) intermediate lung region; and d) peripheral lung region. *: $p<0.01$.

\section{Treatment descriptors}

Pulse rate, oxygen saturation and treatment descriptors (work rate and perceived intensity during treadmill exercise [39, 40], PEP hole diameter and average expiratory pressure) for the 20-min interventions are presented in table 2. Treadmill exercise intensity was rated somewhat severe for breathlessness and strong/ heavy for perceived exertion. All treatments were well tolerated with no adverse events.

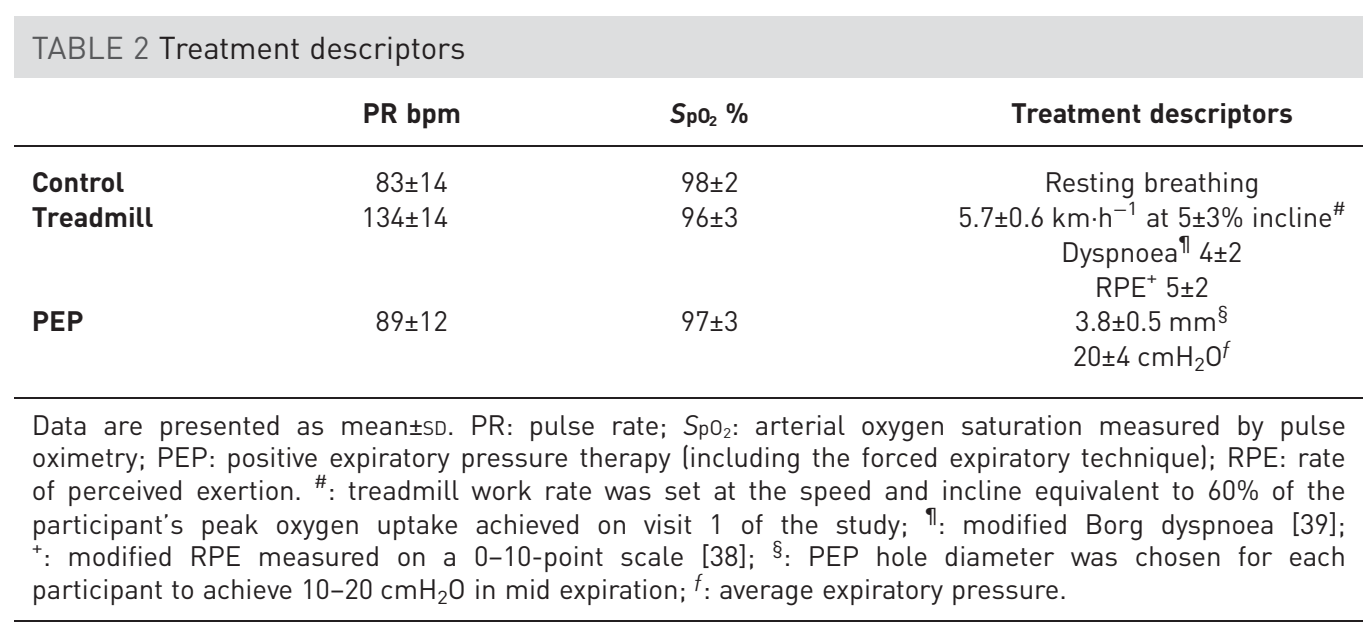




\section{Effect of exercise}

Treadmill exercise cleared significantly more mucus during the intervention compared to control for the whole right lung and intermediate and peripheral regions (table 3 and figure 2) but there was no significant difference in the mucus cleared from the central region. When including the 60 -min follow-up period, treadmill exercise cleared significantly more mucus compared to control for the whole right lung and intermediate and peripheral regions (table 3 and figure 2), but significantly less mucus compared to control for the central region. The improvement in mucus clearance with exercise was primarily achieved during the 20-min intervention, as there was no persistent benefit in the 60-min follow-up period.

There was a nonsignificant trend for participants to do more spontaneous coughs during treadmill exercise compared to control, but there were no differences in the number of coughs between the interventions in the 60-min follow-up period (table 4).

There were no significant differences in the change in sense of chest congestion following treadmill exercise compared to control either immediately after or $60 \mathrm{~min}$ after the intervention (table 5).

\section{Effect of PEP therapy}

PEP therapy cleared significantly more mucus during the intervention compared to control for the whole right lung and all lung regions (table 3 and figure 2). When including the 60-min follow-up period, PEP therapy cleared significantly more mucus compared to control for the whole right lung and all lung regions (table 3 and figure 2). The improvement in mucus clearance with PEP therapy was primarily achieved during the 20-min intervention; there was no persistent benefit in the 60-min follow-up period.

There were significantly more coughs with PEP therapy compared to control during the intervention but no significant difference in the $60 \mathrm{~min}$ following the interventions (table 4).

There was significantly more improvement in the sense of chest congestion following PEP therapy compared to control both immediately after the interventions and $60 \mathrm{~min}$ after the interventions (table 5).

TABLE 3 Mucus clearance

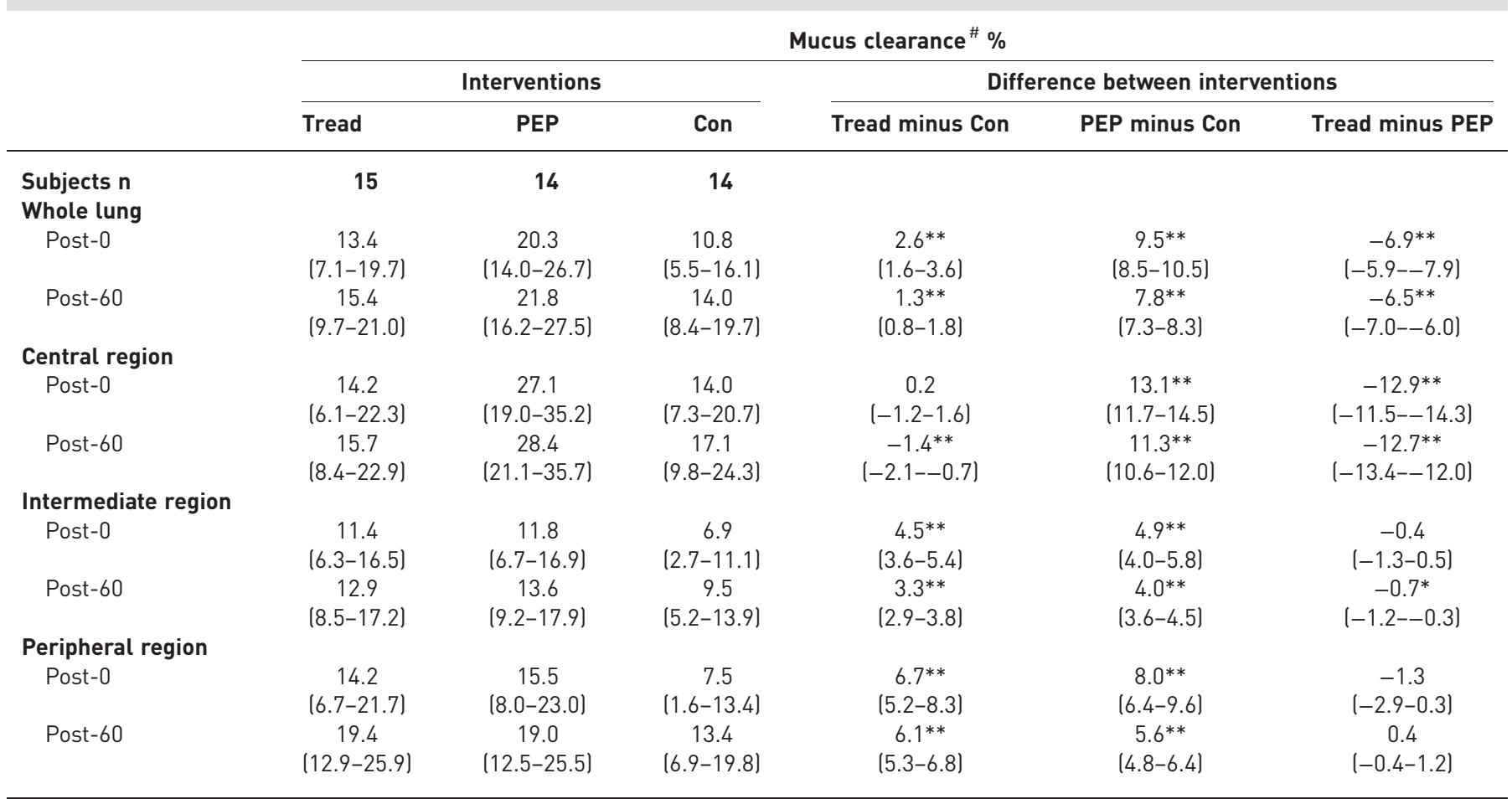

Data are presented as the mean $(95 \% \mathrm{Cl}$ ), unless otherwise stated. Tread: treadmill; PEP: positive expiratory pressure therapy (including the forced expiratory technique); Con: control; Post-0: immediately following intervention; Post-60: 60 min post intervention. \#: assessed immediately after the 20-min intervention, measured as the intercept of the regression coefficient of retention, and the mean retention during the 60 -min resting breathing/recovery follow-up period; ${ }^{*}: p<0.01 ;{ }^{*}: p<0.001$. 


\begin{tabular}{|c|c|c|c|c|c|c|}
\hline \multirow{3}{*}{ Outcome } & \multicolumn{6}{|c|}{ Coughs $n$} \\
\hline & \multicolumn{3}{|c|}{ Interventions } & \multicolumn{3}{|c|}{ Difference between interventions } \\
\hline & Tread & PEP\# & Con & Tread minus Con & PEP minus Con & Tread minus PEP \\
\hline Subjects n & 15 & 14 & 14 & & & \\
\hline During $20-$ min intervention & $16 \pm 23$ & $73 \pm 59$ & $4 \pm 6$ & $\begin{array}{c}13 \\
(-2-27)\end{array}$ & $\begin{array}{c}69 * \\
(33-105)\end{array}$ & $\begin{array}{c}-56^{*} \\
(-87--26)\end{array}$ \\
\hline During 60 -min follow-up & $21 \pm 43$ & $13 \pm 20$ & $13 \pm 15$ & $\begin{array}{c}8 \\
(-17-32)\end{array}$ & $\begin{array}{c}0 \\
(-11-11)\end{array}$ & $\begin{array}{c}8 \\
(-10-25)\end{array}$ \\
\hline
\end{tabular}

Data are presented as mean \pm SD or mean $(95 \% \mathrm{CI})$, unless otherwise stated. Tread: treadmill; PEP: positive expiratory pressure therapy (including the forced expiratory technique); Con: control. \#: participants were instructed to cough 18 times and huff 12 times during the PEP therapy intervention; *: $p<0.01$.

\section{Effect of exercise compared to PEP therapy}

Treadmill exercise cleared significantly less mucus during the intervention compared to PEP therapy for the whole right lung and central region but there was no significant difference in the mucus cleared from the intermediate or peripheral regions (table 3 and figure 2). When including the 60-min follow-up period, treadmill exercise cleared significantly less mucus compared to PEP therapy for the whole right lung and central and intermediate regions but there was no significant difference in the mucus cleared from the peripheral region.

There were significantly fewer coughs with treadmill exercise compared to PEP therapy during the intervention (table 4). There was no significant difference in the number of spontaneous coughs in the 60 min following the interventions (table 4).

There was significantly less improvement in the sense of chest congestion following treadmill exercise compared to PEP therapy both immediately after and $60 \mathrm{~min}$ after the interventions (table 5).

\section{Discussion}

This is the first study to measure mucus clearance, using the gold standard inhaled radioaerosol technique, with exercise alone in adults with CF. The main findings were that although treadmill exercise significantly increased mucus clearance from the whole lung compared to no intervention, treadmill exercise was significantly less effective compared to PEP therapy. There were no significant differences, however, in the amount of mucus cleared from the intermediate and peripheral lung regions when comparing treadmill exercise and PEP therapy.

These results demonstrate that exercise alone does act as an effective independent airway clearance technique for adults with mild to severe CF lung disease in clearing mucus from the intermediate and peripheral lung regions. Importantly, however, less mucus was cleared from the central lung region following treadmill exercise alone compared to PEP therapy, most likely due to the FET component in PEP therapy that involved directed huffing and coughing. Participants did $~ 60$ more coughs during the

TABLE 5 Sense of chest congestion

\begin{tabular}{|c|c|c|c|c|c|c|c|c|c|c|c|c|c|c|c|}
\hline & \multicolumn{9}{|c|}{ Interventions } & \multicolumn{6}{|c|}{ Difference between interventions } \\
\hline & \multicolumn{3}{|c|}{ Pre } & \multicolumn{3}{|c|}{ Post-0 } & \multicolumn{3}{|c|}{ Post-60 } & \multicolumn{3}{|c|}{ Post-0 minus Pre } & \multicolumn{3}{|c|}{ Post-60 minus Post- 0} \\
\hline & Tread & PEP & Con & Tread & PEP & Con & Tread & PEP & Con & $\begin{array}{c}\text { Tread } \\
\text { minus } \\
\text { Con }\end{array}$ & $\begin{array}{c}\text { PEP } \\
\text { minus Con }\end{array}$ & $\begin{array}{c}\text { Tread } \\
\text { minus PEP }\end{array}$ & $\begin{array}{c}\text { Tread } \\
\text { minus Con }\end{array}$ & $\begin{array}{c}\text { PEP } \\
\text { minus Con }\end{array}$ & $\begin{array}{c}\text { Tread } \\
\text { minus PEP }\end{array}$ \\
\hline Subjects $n$ & 15 & 14 & 14 & 15 & 14 & 14 & 15 & 14 & 14 & & & & & & \\
\hline $\begin{array}{l}\text { Chest congestion } \\
\text { VAS }^{\#} \mathrm{~cm}\end{array}$ & $5.2 \pm 1.9$ & $4.2 \pm 1.9$ & $5.9 \pm 1.8$ & $6.1 \pm 1.9$ & $5.9 \pm 2.2$ & $6.4 \pm 1.9$ & $5.4 \pm 2.1$ & $6.1 \pm 1.7$ & $6.0 \pm 2.0$ & $\begin{array}{c}0.5 \\
(-0.3-1.3)\end{array}$ & $\begin{array}{c}1.2^{*} \\
(0.1-2.3)\end{array}$ & $\begin{array}{c}0.7^{*} \\
(0.1-1.4)\end{array}$ & $\begin{array}{c}0.1 \\
(-0.7-1.0)\end{array}$ & $\begin{array}{c}1.8^{* * *} \\
(0.9-2.7)\end{array}$ & $\begin{array}{c}1.7^{* *} \\
(0.7-2.7)\end{array}$ \\
\hline
\end{tabular}


PEP intervention than during treadmill exercise, which in turn resulted in $\sim 10$ more coughs than during the control intervention. The absence of a matched "cough control" day in our study prevents the determination of how much the improvement in mucus clearance was due to treadmill exercise and PEP breathing, compared to the benefits achieved with cough alone. Previous studies have demonstrated that FET alone is an effective treatment $[17,41]$ and interventions that include FET and/or directed coughing clear mucus predominantly from the central regions $[16,18,42]$. Perhaps if FET or directed coughing had been included with the treadmill intervention there would have been more mucus cleared from the central region.

The baseline mucus clearance (i.e. that achieved during the resting breathing (control) intervention) in this study was very similar to that reported in the most comprehensive study of adults with CF (in our study $\sim 15 \%$ was cleared from the whole lung $60 \mathrm{~min}$ post inhalation of the radioaerosol compared to $14 \%$ clearance in RoBinson et al. [29]). This amount of mucus clearance in people with CF is about half that of the group of healthy aged-matched control participants, which was reported as $28 \%$ clearance from the whole lung [29]. Despite the vast majority of the participants in our study carrying out well-established airway clearance routines (14 out of 15 were prescribed mucolytic and/or osmotic medication and 14 out of 15 performed some form of airway clearance regularly), it would appear that mucus clearance remains markedly reduced in adults with $\mathrm{CF}$, further highlighting the ongoing need to optimise airway clearance therapies.

The improvements in mucus clearance with exercise and PEP therapy were primarily achieved during the 20-min intervention. There was no persistent benefit or acceleration of mucus clearance created by the treatments in the 60-min follow-up period, which is consistent with every previous study that has included a follow-up period after an airway clearance treatment in adults with CF [15-18]. By contrast, the mucolytic and osmotic medications hypertonic saline [28,30] and mannitol [31] improve mucus clearance immediately following inhalation and continue to accelerate mucus clearance in the follow-up period. One clinical implication is that, given that there is no continued benefit to mucus clearance after the initial effects of airway clearance interventions, people with CF will need to regularly perform these treatments to maintain adequate mucus clearance.

The improvement in whole lung mucus clearance with exercise $(\sim 3 \%$ more than during the control intervention) seen in our study was less than the $8-9 \%$ improvement found in earlier studies in people without lung disease [13] and adults with chronic bronchitis [14]. The improvement in peripheral lung region mucus clearance, however, was similar ( $7 \%$ in our study compared to $6 \%$ ) [14]. It is not clear why there was a discrepancy in the effect for the whole lung, given that participants in our study exercised at a similar intensity to those in the other two studies $[13,14]$. The baseline mucus clearance in our study was greater than that seen in those with chronic bronchitis (in our study $\sim 15 \%$ was cleared from the whole lung $60 \mathrm{~min}$ post inhalation of the radioaerosol compared to $10 \%$ clearance in those with chronic bronchitis) [14]. Perhaps because most of the participants in our study already had well-established airway clearance routines, there was less potential for an improvement in mucus clearance with exercise. Another possibility is that in our study radioaerosol deposition was predominantly in the central lung region, which had the least improvement in mucus clearance, and thus may have lowered the overall whole lung mucus clearance owing to the greater relative contribution of this region. It should also be noted that because mucus clearance from the peripheral and intermediate lung regions was greater with exercise compared to the control, more mucus would have been entering the central region during the exercise intervention, which would likely lower the net mucus clearance from this region.

The improvement in whole lung mucus clearance with PEP therapy in our study $(\sim 10 \%$ more than during the control intervention) is similar to the 5-20\% improvement that has been reported previously [17, 18, 43]. Also similar to previous research, the main increase in mucus clearance was in the central lung region [18]. Interestingly, trials that have compared PEP therapy to FET or directed coughing alone have shown no between-group differences in mucus clearance [17, 44] or dry weight of expectorated sputum [45] immediately following the PEP interventions. Another study that investigated PEP therapy compared to PEP alone (i.e. no FET or directed coughing) found that although there were no between-group differences in lung function, expectorated sputum weight or exacerbation frequency, participants reported PEP alone to be ineffective in clearing mucus [46]. In combination, these studies would suggest that the FET component of PEP therapy makes an important contribution to the efficacy of PEP therapy.

Exercise cleared significantly less mucus than PEP therapy for the whole lung and central lung region ( $\sim \%$ and $13 \%$, respectively) in our study, with no significant differences in the intermediate or peripheral lung regions. The only other study which compared exercise alone to PEP therapy found that exercise alone produced significantly less sputum than PEP therapy [47]. This study, however, has only been published in abstract form and lacks details on CF participant characteristics, exercise intensity, the PEP 
protocol and results data. Two studies have compared exercise plus FET or directed coughing to PEP therapy and found no between-group differences in mucus clearance [19] or expectorated sputum weight [48]. However, all of these studies, including our study, involved participants who were not taking CFTR modulators. Considering the likely improvement in mucus clearance with these highly effective therapies, it is possible that the effects of airway clearance techniques may change once patients with CF are routinely prescribed these new medications.

This study has demonstrated that a single bout of treadmill exercise improved whole lung mucus clearance compared to no intervention; however, exercise alone was less effective than the well-established airway clearance technique of PEP therapy, which includes huffing and coughing. In terms of the effects of the two interventions on the different lung regions, there were no differences in the amount of mucus cleared from the peripheral and intermediate regions, yet significantly less mucus was cleared from the central region with exercise alone. This difference was most likely due to the huffing and coughing in the FET component of PEP therapy. In clinical practice, therefore, it is recommended that FET is included with exercise if the aim is to improve central and whole lung mucus clearance. Longer-term studies investigating exercise (with huffing and coughing) as a standalone airway clearance technique are required to determine if it is as effective as established airway clearance techniques on clinically important outcomes, such as exacerbation frequency, quality of life and exercise capacity, which are related to morbidity and mortality in CF.

Conflict of interest: None declared.

Support statement: This project was funded by an LJ Hooker CF Research Trust Fund Grant from the Australian Cystic Fibrosis Research Trust. Funding information for this article has been deposited with the Crossref Funder Registry.

\section{References}

Robinson M, Bye PTB. Mucociliary clearance in cystic fibrosis. Pediatr Pulmonol 2002; 33: 293-306.

2 Association of Chartered Physiotherapists in Cystic Fibrosis. Standards of Care and Good Clinical Practice for the Physiotherapy Management of Cystic Fibrosis. 3rd Edn. London, UK Cystic Fibrosis Trust, 2017.

3 Button BM, Wilson C, Dentice R, et al. Physiotherapy for cystic fibrosis in Australia and New Zealand: a clinical practice guideline. Respirology 2016; 21: 656-667.

4 Flume PA, Robinson KA, O'Sullivan BP, et al. Cystic fibrosis pulmonary guidelines: airway clearance therapies. Respir Care 2009; 54: 522-537.

5 Smyth AR, Bell SC, Bojcin S, et al. European Cystic Fibrosis Society standards of care: best practice guidelines. J Cyst Fibros 2014; 13: Suppl. 1, S23-S42.

6 Sawicki GS, Sellers DE, Robinson WM. High treatment burden in adults with cystic fibrosis: challenges to disease self-management. J Cyst Fibros 2009; 8: 91-96.

7 Baldwin DR, Hill AL, Peckham DG, et al. Effect of addition of exercise to chest physiotherapy on sputum expectoration and lung function in adults with cystic fibrosis. Respir Med 1994; 88: 49-53.

8 Salh W, Bilton D, Dodd M, et al. Effect of exercise and physiotherapy in aiding sputum expectoration in adults with cystic fibrosis. Thorax 1989; 44: 1006-1008.

9 Zach MS, Purrer B, Oberwaldner B. Effect of swimming on forced expiration and sputum clearance in cystic fibrosis. Lancet 1981; 2: 1201-1203.

10 Radtke T, Nevitt SJ, Hebestreit H, et al. Physical exercise training for cystic fibrosis. Cochrane Database Syst Rev 2017; 11: CD002768.

11 Donaldson SH, Corcoran TE, Laube BL, et al. Mucociliary clearance as an outcome measure for cystic fibrosis clinical research. Proc Am Thorac Soc 2007; 4: 399-405.

12 van der Schans CP. Airway clearance: assessment of techniques. Paediatr Respir Rev 2002; 3: 110-114.

13 Wolff RK, Dolovich MB, Obminski G, et al. Effects of exercise and eucapnic hyperventilation on bronchial clearance in man. J Appl Physiol 1977; 43: 46-50.

14 Oldenburg FA Jr, Dolovich MB, Montgomery JM, et al. Effects of postural drainage, exercise, and cough on mucus clearance in chronic bronchitis. Am Rev Respir Dis 1979; 120: 739-745.

15 Elkins M, Eberl S, Constable C, et al. The effect of manual chest physiotherapy, positive expiratory pressure (PEP), and oscillating PEP on mucociliary clearance in subjects with cystic fibrosis. Pediatric Pulmonology 2005; 40: Suppl. 28, 321, A377.

16 Rossman CM, Waldes R, Sampson D, et al. Effect of chest physiotherapy on the removal of mucus in patients with cystic fibrosis. Am Rev Respir Dis 1982; 126: 131-135.

17 Falk M, Mortensen J, Kelstrup M, et al. Short-term effects of positive expiratory pressure and the forced expiration technique on mucus clearance and lung function in CF. Pediatric Pulmonology 1993; 16: Suppl. 9, 268, A241.

18 Mortensen J, Falk M, Groth S, et al. The effects of postural drainage and positive expiratory pressure physiotherapy on tracheobronchial clearance in cystic fibrosis. Chest 1991; 100: 1350-1357.

19 Lannefors L, Wollmer P. Mucus clearance with three chest physiotherapy regimes in cystic fibrosis: a comparison between postural drainage, PEP and physical exercise. Eur Respir J 1992; 5: 748-753.

20 McIlwaine M, Button B, Dwan K. Positive expiratory pressure physiotherapy for airway clearance in people with cystic fibrosis. Cochrane Database Syst Rev 2015; 6: CD003147.

21 Fuchs HJ, Borowitz DS, Christiansen DH, et al. Effect of aerosolized recombinant human DNase on exacerbations of respiratory symptoms and on pulmonary function in patients with cystic fibrosis. N Engl J Med 1994; 331: 637-642. 
22 Australian Radiation Protection and Nuclear Safety Agency. Code of Practice: Exposure of Humans to Ionizing Radiation for Research Purposes. Radiation Protection Series Publication No. 8. Yallambie, ARPANSA, 2005.

23 American College of Sports Medicine. ACSM's guidelines for exercise testing and prescription. Philadelphia, Wolters Kluwer/Lippincott Williams \& Wilkins Health, 2014.

24 Pryor J. The forced expiration technique. In: Pryor J, ed. Respiratory Care. Edinburgh, Churchill Livingstone, 1991; pp. 79-100.

25 Lannefors L, Eriksson L. Positive expiratory pressure (PEP). In: Mcllwaine M, Van Ginderdeureni F, eds. Physiotherapy for people with Cystic Fibrosis: from Infant to Adult. Karup, International Physiotherapy Group/ Cystic Fibrosis, 2009; pp. 12-14.

26 Daviskas E, Anderson SD, Gonda I, et al. Changes in mucociliary clearance during and after isocapnic hyperventilation in asthmatic and healthy subjects. Eur Respir J 1995; 8: 742-751.

27 Regnis JA, Robinson M, Bailey DL, et al. Mucociliary clearance in patients with cystic fibrosis and in normal subjects. Am J Respir Crit Care Med 1994; 150: 66-71.

28 Robinson M, Hemming AL, Regnis JA, et al. Effect of increasing doses of hypertonic saline on mucociliary clearance in patients with cystic fibrosis. Thorax 1997; 52: 900-903.

29 Robinson M, Eberl S, Tomlinson C, et al. Regional mucociliary clearance in patients with cystic fibrosis. J Aerosol Med 2000; 13: 73-86.

30 Robinson M, Regnis JA, Bailey DL, et al. Effect of hypertonic saline, amiloride, and cough on mucociliary clearance in patients with cystic fibrosis. Am J Respir Crit Care Med 1996; 153: 1503-1509.

31 Robinson M, Daviskas E, Eberl S, et al. The effect of inhaled mannitol on bronchial mucus clearance in cystic fibrosis patients: a pilot study. Eur Respir J 1999; 14: 678-685.

32 Daviskas E, Anderson SD, Eberl S, et al. Effects of terbutaline in combination with mannitol on mucociliary clearance. Eur Respir J 2002; 20: 1423-1429.

33 Daviskas E, Anderson SD, Eberl S, et al. Effect of increasing doses of mannitol on mucus clearance in patients with bronchiectasis. Eur Respir J 2008; 31: 765-772.

34 Daviskas E, Anderson SD, Eberl S, et al. Beneficial effect of inhaled mannitol and cough in asthmatics with mucociliary dysfunction. Respir Med 2010; 104: 1645-1653.

35 Phipps PR, Gonda I, Bailey DL, et al. Comparisons of planar and tomographic gamma scintigraphy to measure the penetration index of inhaled aerosols. Am Rev Respir Dis 1989; 139: 1516-1523.

36 Drinkwater BL, Horvath SM, Wells CL. Aerobic power of females, ages 10 to 68. J Gerontol 1975; 30: 385-394.

37 Froelicher VF Jr, Allen M, Lancaster MC. Maximal treadmill testing of normal USAF aircrewmen. Aerosp Med 1974; 45: 310-315.

38 Quanjer PH, Stanojevic S, Cole TJ, et al. Multi-ethnic reference values for spirometry for the 3-95-yr age range: the global lung function 2012 equations. Eur Respir J 2012; 40: 1324-1343.

39 Borg GA. Psychophysical bases of perceived exertion. Med Sci Sports Exerc 1982; 14: 377-381.

40 Mahler DA, Mejia-Alfaro R, Ward J, et al. Continuous measurement of breathlessness during exercise: validity, reliability, and responsiveness. J Appl Physiol 2001; 90: 2188-2196.

41 Sutton PP, Parker RA, Webber BA, et al. Assessment of the forced expiration technique, postural drainage and directed coughing in chest physiotherapy. Eur J Respir Dis 1983; 64: 62-68.

42 Bateman JR, Newman SP, Daunt KM, et al. Is cough as effective as chest physiotherapy in the removal of excessive tracheobronchial secretions? Thorax 1981; 36: 683-687.

43 van Hengstum M, Festen J, Beurskens C, et al. The effect of positive expiratory pressure versus forced expiration technique on tracheobronchial clearance in chronic bronchitics. Scand J Gastroenterol 1988; 23: Suppl. 143, $114-118$.

44 van der Schans CP, van der Mark TW, de Vries G, et al. Effect of positive expiratory pressure breathing in patients with cystic fibrosis. Thorax 1991; 46: 252-256.

45 Placidi G, Cornacchia M, Polese G, et al. Chest physiotherapy with positive airway pressure: a pilot study of short-term effects on sputum clearance in patients with cystic fibrosis and severe airway obstruction. Respir Care 2006; 51: 1145-1153.

46 Steen HJ, Redmond AO, O'Neill D, et al. Evaluation of the PEP mask in cystic fibrosis. Acta Paediatr Scand 1991 80: 51-56.

47 Falk M, Kelstrup M, Andersen JB, et al. PEP treatment or physical exercise - effects on secretions expectorated and indices of central and peripheral airway function. A controlled study. In: Proceedings of the 10th International Cystic Fibrosis Congress. Hong Kong, Excerpta Medica Asia, 1988.

48 Aquino A, Balestri E, Dall'Ara S, et al. Efficacy of physical exercise playing a video game for mucus clearance in patients with cystic fibrosis. J Cyst Fibrosis 2006; 5: Suppl. 1, S83. 